\title{
Resonant or Not, Two Amplification Modes of Proprioceptive Inputs by Persistent Inward Currents in Spinal Motoneurons
}

\author{
Marin Manuel, Claude Meunier, Maud Donnet, and Daniel Zytnicki \\ Laboratoire de Neurophysique et Physiologie, Centre National de la Recherche Scientifique/Université Paris-Descartes, Unite Mixte de Recherche 8119, \\ 75270 Paris Cedex 06, France
}

\begin{abstract}
Why do motoneurons possess two persistent inward currents (PICs), a fast sodium current and a slow calcium current? To answer this question, we replaced the natural PICs with dynamic clamp-imposed artificial PICs at the soma of spinal motoneurons of anesthetized cats. We investigated how PICs with different kinetics $(1-100 \mathrm{~ms})$ amplify proprioceptive inputs. We showed that their action depends on the presence or absence of a resonance created by the $I_{\mathrm{h}}$ current. In resonant motoneurons, a fast PIC enhances the resonance and amplifies the dynamic component of Ia inputs elicited by ramp-and-hold muscle stretches. This facilitates the recruitment of these motoneurons, which likely innervate fast contracting motor units developing large forces, e.g., to restore balance or produce ballistic movements. In nonresonant motoneurons, in contrast, a fast PIC easily triggers plateau potentials, which leads to a dramatic amplification of the static component of Ia inputs. This likely facilitates the recruitment of these motoneurons, innervating mostly slowly contracting and fatigue-resistant motor units, during postural activities. Finally, a slow PIC may switch a resonant motoneuron to nonresonant by counterbalancing $I_{\mathrm{h}}$, thus changing the action of the fast PIC. A modeling study shows that $I_{\mathrm{h}}$ needs to be located on the dendrites to create the resonance, and it predicts that dendritic PICs amplify synaptic input in the same manner as somatic PICs.
\end{abstract}

Key words: proprioception; subthreshold resonance; persistent sodium current; persistent calcium current; hyperpolarization activated mixed cationic current; dynamic clamp

\section{Introduction}

The persistent sodium current $\left(I_{\mathrm{NaP}}\right)$ is ubiquitous in neurons (Crill, 1996; D’Angelo et al., 1998; Kay et al., 1998). It activates below the spike threshold with a time constant of the order of the millisecond (Crill, 1996). It amplifies synaptic inputs (Schwindt and Crill, 1995) and promotes spike initiation (Kuo et al., 2006), repetitive firing (Lee and Heckman, 2001; Harvey et al., 2006a), and bursting (Wu et al., 2005). It may also enhance subthreshold resonances (Gutfreund et al., 1995; Hutcheon et al., 1996; Hutcheon and Yarom, 2000). Many neurons (Sayer et al., 1993; Morisset and Nagy, 2000; Kononenko and Dudek, 2006) are also endowed with a persistent calcium current $\left(I_{\mathrm{CaL}}\right)$, mediated by L-type channels. This current was first described in spinal motoneurons. As $I_{\mathrm{NaP}}$, it activates below the spike threshold, but it is slower (Schwindt and Crill, 1984; Carlin et al., 2000; Mermelstein et al., 2000; Li and Bennett, 2003). It is responsible for plateau potentials in motoneurons (Schwindt and Crill, 1980; Conway et

Received July 20, 2007; revised Sept. 14, 2007; accepted 0ct. 6, 2007.

This work was supported by the Association Française contre les Myopathies (Maladies neuromusculaires 22004 Grant 10737) and by the Ministère de la Recherche (Action Concertée Incitative "Neurosciences Intégratives et Computationnelles"). M.M. was a research fellow of Délégation Générale pour l'Armement. We are indebted to Hervé Suaudeau for his invaluable technical assistance.

Correspondence should be addressed to Dr. Marin Manuel, Laboratoire de Neurophysique et Physiologie, Unité Mixte de Recherche 8119, Centre National de la Recherche Scientifique/Université Paris-Descartes, 45 rue des SaintsPères, 75270 Paris Cedex 06, France. E-mail: marin.manuel@univ-paris5.fr.

DOI:10.1523/JNEUROSCI.3299-07.2007

Copyright $\odot 2007$ Society for Neuroscience 0270-6474/07/2712977-12\$15.00/0 al., 1988; Hounsgaard and Mintz, 1988) and causes a counterclockwise hysteresis of their current-frequency relationship (Conway et al., 1988). It is located not only in the dendrites but also in the soma (Ballou et al., 2006).

Both persistent inward currents (PICs) may augment the effective synaptic current that reaches the spike initiation zone of motoneurons (Powers and Binder, 2001; Prather et al., 2001; Lee et al., 2003), thereby increasing the firing frequency (Lee and Heckman, 2000; Hultborn et al., 2003; Lee et al., 2003). In cat spinal motoneurons, they can amplify synaptic inputs elicited by muscle stretches or tendon vibration (Bennett et al., 1998; Lee and Heckman, 2000; Jones and Lee, 2006). This raises the question of the respective contributions of the two PICs to the amplification of synaptic inputs. To what extent is this amplification determined by PIC kinetics? How do fast and slow PICs interact to amplify Ia monosynaptic excitatory inputs, which arise from spindle primary endings and constitute the main proprioceptive input to motoneurons?

These issues required the comparison of EPSPs recorded with and without PICs in the same motoneuron. Moreover, the effects of fast and slow PICs had to be tested separately and concurrently. In in vivo experiments, this cannot be achieved by manipulating the natural PICs pharmacologically. We relied on dynamicclamp experiments to add artificial currents that mimicked PICs to motoneurons of anesthetized cats, in which the natural PICs were strongly depressed (Guertin and Hounsgaard, 1999; Lee and 
Heckman, 2000). The conductance and activation kinetics of artificial PICs could be modified at will, and we assessed how the amplification of synaptic input depended on the activation time constant of the current. Our study unravels how slow and fast PICs control the amplification. Amplification involves a resonance created by $I_{\mathrm{h}}$. The analysis of a simple motoneuron model further suggests that the resonance occurs only if the dendrites are endowed with $I_{\mathrm{h}}$ current and that dendritic PICs have similar effects as somatic ones.

\section{Materials and Methods}

Animal preparation. Experiments were performed on 17 adult cats (3.2$4.1 \mathrm{~kg}$ ) deeply anesthetized with sodium pentobarbitone (Pentobarbital; Sanofi Recherche, Montpellier, France). In accordance with French legislation, the investigators had valid licenses to perform experiments on live vertebrates delivered by the Direction des Services Vétérinaires (Préfecture de Police, Paris, France). The animal house and the experimental room had received the agreement of the same authority. Anesthesia was induced with an intraperitoneal injection $(45 \mathrm{mg} / \mathrm{kg})$, supplemented whenever necessary (usually every $2 \mathrm{~h}$ ) by intravenous injections (3-6 $\mathrm{mg} / \mathrm{kg}$ ). Animals were paralyzed with Pancuronium Bromide (Pavulon; Organon, Puteaux, France) at a rate of $0.4 \mathrm{mg} / \mathrm{h}$ and artificially ventilated (end-tidal $\mathrm{P}_{\mathrm{CO}_{2}}$ maintained at $\sim 4 \%$ ). A bilateral pneumothorax prevented movements of the rib cage. The adequacy of anesthesia was assessed on myotic pupils and on the stability of blood pressure (measured in the carotid) and of heart rate. At the onset of experiment, amoxicillin (500 mg; Clamoxyl; Merieux, Marcy l'Etoile, France) and methylprenidsolone (5 mg; Solu-Medrol; Pfizer, New York, NY) were given subcutaneously to prevent the risk of infection and edema, respectively. The central temperature was kept at $38^{\circ} \mathrm{C}$. Blood pressure was maintained above $90 \mathrm{mmHg}$ by perfusion of a $4 \%$ glucose solution containing $\mathrm{NaHCO}_{3}(1 \%)$ and gelatin (14\%; Plasmagel, Roger Bellon Laboratories, Neuilly, France) at a rate of $3-12 \mathrm{ml} / \mathrm{h}$. A catheter allowed evacuation of urine from the bladder. At the end of the experiments, animals were killed with a lethal intravenous injection of pentobarbitone $(250 \mathrm{mg})$.

The following nerves were cut, dissected, and mounted on a pair of stimulating electrodes to identify recorded motoneurons: anterior biceps and semimenbranosus taken together (ABSm), posterior biceps and semitendinosus taken together (PBSt), the plantaris nerve, the remaining part of the tibialis nerve (Tib), and the common peroneal (CP) nerve. The gastrocnemius medialis together with gastrocnemius lateralis and soleus nerves [Triceps surae (TS)] were carefully dissected and left uninterrupted. They were mounted on a monopolar electrode for stimulation and electroneurographic recordings. The Achilles tendon, along with a bone fragment from the calcaneus, was fastened to a muscle puller $(310 \mathrm{~B}$ muscle lever; Aurora Scientific, Aurora, Ontario, Canada). This device also allowed us to record the passive muscle force. The lumbosacral spinal segments were exposed by laminectomy, and the tissues in hindlimb and spinal cord were covered with pools of mineral oil kept at $38^{\circ} \mathrm{C}$.

In one experiment, we injected intrathecally ZD-7288 (4ethylphenylamino-1,2-dimethyl-6-methylaminopyrimidinium chloride), a selective blocker of the $I_{\mathrm{h}}$ current (Harris and Constanti, 1995; Pape, 1996). The catheter was inserted through the dura under the ventral side of the spinal cord, slid at the L5 level, and gently pushed backwards until its end reached approximately the L6/L7 limit. In in vitro preparations, concentrations of 100-200 $\mu \mathrm{M}$ ZD-7288 are usually applied to the bath to block the $I_{\mathrm{h}}$ current (Kiehn et al., 2000; Chevallier et al., 2006). We used a much higher concentration (10 mM) because in our experimental conditions the drug was drained by the CSF and had to diffuse through a thick layer of myelinated fibers before reaching the motoneuron pools in the ventral horn.

Recordings. Part of motoneuron recordings were done using micropipettes (tip diameter, $2.0-2.5 \mu \mathrm{m}$ ) filled with $\mathrm{KCl}$ at $3 \mathrm{M}$ (resistance, 2-4 $\mathrm{M} \Omega$ ). It proved rather difficult to avoid spiking in these conditions. Therefore, we also used micropipettes filled with a mixture of QX-314 [2(triethylamino)- $N$-(2,6-dimethylphenyl) acetamine] (100 mM; Sigma, St. Louis, $\mathrm{MO}$ ) and $\mathrm{KCl}$ at $3 \mathrm{~m}$ (resistance, $3-8 \mathrm{M} \Omega$ ) to block sodium currents. Similar results were obtained in both cases, and therefore we pooled the data together. Intracellular recordings of motoneurons were made using the Axoclamp 2B amplifier (Molecular Devices, Palo Alto, CA) connected to a Power1401 interface and using the Spike2 software (Cambridge Electronic Design, Cambridge, UK).

After impalement, identification of motoneurons rested on the observation of antidromic action potentials in response to the electrical stimulation of their axon in a peripheral nerve, before blockade by QX-314 All motoneurons retained for analysis had a resting membrane potential more hyperpolarized than $-50 \mathrm{mV}$, which varied by $<5 \mathrm{mV}$ over the recording session. The axonal conduction velocity was computed from the latency of the antidromic action potentials. A series of small amplitude ( -5 to $+5 \mathrm{nA}$ by $1 \mathrm{nA}$ increments) $500 \mathrm{~ms}$ square current pulses were used to measure the peak input conductance and the plateau conductance of the neuron. The "sag ratio" of the voltage response was then computed as the ratio of the plateau conductance over the peak conductance (Manuel et al., 2005).

Dynamic-clamp-generated PICs. Recordings were done using the discontinuous current-clamp mode $(7-9 \mathrm{kHz})$ of the amplifier because it allows for reliable measurements of the membrane potential, even when large currents are injected (Brizzi et al., 2004; Prinz et al., 2004). The dynamic-clamp current $I_{\text {PIC }}$ was injected into the motoneuron soma through the recording micropipette. It was computed by a personal computer running RT-Linux (a Linux kernel modified to achieve hard realtime processing) and the dynamic-clamp software MRCI (Raikov et al., 2004). The system allows the computation at a speed of $10 \mathrm{kHz}$ of the equations $I_{\mathrm{PIC}}=\bar{g}_{\mathrm{PIC}} \times w \times\left(E_{\mathrm{PIC}}-V\right), \tau_{\mathrm{PIC}} \times d w / d t=w_{\infty}(V)-w$, and $w_{\infty}(V)=1 / 1+\exp \left(\left(V-\theta_{\text {PIC }}\right) / k_{\text {PIC }}\right.$, where $\bar{g}_{\text {PIC }}$ is the maximal conductance of the PIC current, $w$ is its activation variable, $E_{\mathrm{PIC}}$ its reversal potential, $V$ is the membrane potential, $\tau_{\text {PIC }}$ is the activation time constant, $w_{\infty}(V)$ is the steady-state activation curve, $\theta_{\mathrm{PIC}}$ is the halfactivation voltage, and $k_{\text {PIC }}$ determines the slope of the activation current.

We did not attempt to use supposedly realistic values for parameterizing PICs. Indeed, PICs parameters have never been firmly established. Moreover, they are likely to vary from one motoneuron to the other. Rather, we used reasonable values allowing for a sufficient activation of $I_{\mathrm{PIC}}$ in response to sinusoidal currents and EPSPs generated by muscle stretching. We set $E_{\text {PIC }}$ to $+80 \mathrm{mV}, k_{\text {PIC }}$ to $-4 \mathrm{mV}$, and the halfactivation voltage, $\theta_{\mathrm{PIC}}$, to $\sim 10 \mathrm{mV}$ above the resting membrane potential (Schwindt and Crill, 1984; Li and Bennett, 2003). With these parameters, $8 \%$ of the PIC is activated at rest in steady-state conditions and $12 \%$ when the motoneuron is depolarized by $2 \mathrm{mV}$. The overlap between the activation curves of PICs and $I_{\mathrm{h}}$, which is also partially activated at rest, was then sufficient to allow these currents to interact. We choose $\bar{g}_{\text {PIC }}$ in the range of $25-150 \mathrm{nS}$. These values were large enough to produce substantial amplification of inputs yet small enough to avoid plateau potentials in the motoneurons that displayed substantial sag in their response to current steps.

Everything being equal, we tested the effect of artificial PICs when the activation time constant, $\tau_{\text {PIC }}$, was varied between a short value $(1 \mathrm{~ms})$ and large values (up to $100 \mathrm{~ms}$ ). The shortest time constants (1-2 ms) are comparable with the activation time constant of the persistent sodium current. Larger time constants $(20-100 \mathrm{~ms})$ covered the probable range of the natural calcium persistent currents. We also successfully investigated the combined effect of a slow (50 or $100 \mathrm{~ms}$ ) and a fast PIC (1 ms) in a few motoneurons in which recording conditions remained exceptionally stable.

Muscle stretches. The triceps surae muscle was stretched with the muscle puller. The initial length, $l_{0}$, corresponded to a passive force of $0.3 \mathrm{~N}$ and was within the physiological range (Fetz et al., 1979). Two stretching protocols were used. In the sinusoidal protocol, the amplitude was constant $\left( \pm 0.5 \mathrm{~mm}\right.$ around $l_{0}$, i.e., $1 \mathrm{~mm}$ peak-to-peak), and, after each cycle, the frequency of the sine wave was incremented by $1 \mathrm{~Hz}$ to explore the range of $1-25 \mathrm{~Hz}$. We checked in four motoneurons that decrementing the stretch frequency from 25 to $1 \mathrm{~Hz}$ did not affect the results. In the ramp-and-hold protocol, the muscle was stretched, starting from $l_{0}$, with a ramp of $10 \mathrm{~mm} / \mathrm{s}$ until the muscle was lengthened by $1 \mathrm{~mm}$. The muscle length was then held for $2 \mathrm{~s}$ before the muscle was shortened back to $l_{0}$ with a ramp of same velocity. Electroneurographic recordings allowed us 
to check that the two protocols efficiently activated spindle afferents. A ramp velocity of $10 \mathrm{~mm} / \mathrm{s}$ was chosen because it elicited a substantial dynamic discharge of primary endings (Matthews, 1963). Recordings in motoneurons were made while the muscle was stretched, in control condition (without PIC) and for each value of the artificial PIC time constant. In each condition, two to five sequences of stretches were applied to the muscle with a delay of $2 \mathrm{~s}$ between the end of a sequence and the beginning of the next. The recordings were averaged off-line before any measurement.

Frequency-response curves. We used the impedance amplitude profile (ZAP) method to characterize the resonant behavior of the cells (Puil et al., 1988; Hutcheon and Yarom, 2000). We generated a sine wave current $I_{\mathrm{ZAP}}(t)=a \times \sin \left(b t^{k}\right)$ of $10 \mathrm{~s}$ with the Power1401. The amplitude $a$ was always set to $2 \mathrm{nA}$. The frequency, which is the derivative of the phase $b t^{k}$, increased as $t^{2}(k=3)$ from 0 to $40 \mathrm{~Hz}$. We verified in five motoneurons that the results were not affected when the frequency increased linearly $(k=2)$ and when the frequency decreased in time. We recorded at least three voltage responses in control condition (without artificial PIC) and for each value of $\tau_{\text {PIC }}$. Each series was averaged off-line. We then calculated the ratio of the fast Fourier transforms of the voltage response and of the ZAP current input, and we plotted its modulus against the frequency, yielding the frequency-response curve (FRC). This curve was smoothened by a running average with a window of $2 \mathrm{~Hz}$. A resonance of the neuron corresponded to a peak of the FRC at a preferred frequency (Hutcheon and Yarom, 2000). The acuity of the resonance was quantified by the quality factor $Q$, defined as the ratio of the frequency response at the resonance frequency to the response at low frequency (in our case, $1 \mathrm{~Hz}$ ). When there was no resonance, $Q$ was set to 1.0 .

Modeling. To investigate how the somatic and dendritic components of $I_{\mathrm{h}}$ and of fast and slow PICs affected the FRC of motoneurons, we computed the impedance $Z(\omega)$ of a motoneuron model. We used a variant of Rall's model (Rall, 1959) with active conductances. The detailed morphology of the neuron was not taken into account, dendrites being simply described by an equivalent cylinder of diameter $d$, length $l$, and axial resistivity $R_{i}$, with sealed distal end. The somatic and dendritic voltages, $V^{\mathrm{S}}$ and $V^{\mathrm{D}}$, were governed by the coupled equations:

$$
\begin{gathered}
C_{m} S \frac{d V^{S}}{d t}=G_{l}^{S} S\left(V_{l}^{S}-V^{S}\right)+G_{h}{ }^{S} S z_{h}\left(V_{h}-V^{S}\right)+G_{\mathrm{PIC}}{ }^{S} S z_{\mathrm{PIC}}\left(V_{\mathrm{PIC}}\right. \\
\left.-V^{S}\right)+\frac{\pi d^{2} \partial V^{D}(0, t)}{4 R_{i} \partial x}+I^{S}(t) \\
C_{m} \frac{\partial V^{D}}{\partial t}=G_{l}{ }^{D}\left(V_{l}^{D}-V^{D}\right)+G_{h}{ }^{D} z_{h}\left(V_{h}-V^{D}\right)+G_{\mathrm{PIC}}^{D} z_{\mathrm{PIC}}\left(V_{\mathrm{PIC}}-V^{D}\right) \\
+\frac{d \partial^{2} V^{D}}{4 R_{i} \partial x^{2}},
\end{gathered}
$$

where $C_{m}$ is the specific capacitance, $S$ is the membrane area of the soma, and $I^{\mathrm{S}}(t)$ is the current injected into the soma through the micropipette. The somatic and dendritic leak current had conductance per unit area $G_{l}^{S}$ and $G_{l}^{V}$ and reversal potentials $V_{l}^{S}$ and $V_{l}^{D}$. The somatic $I_{\mathrm{h}}$ current had reversal potential $V_{\mathrm{h}}$ and maximal conductance $G_{h}^{S}$ (per unit area). Its activation variable, $z_{h}$, followed the kinetic equation:

$$
\tau_{h} \frac{d z_{h}}{d t}=z_{h}^{S S}(V)-z_{h}
$$

where $z_{h}^{S S}(V)$ was the steady-state activation of the current. The dendritic $I_{\mathrm{h}}$ current had same kinetics. Its conductance was uniform and equal to $G_{h}^{D}$. Similarly, the somatic and dendritic components of the PIC had maximal conductance $G_{\text {PIC }}^{S, D}$ and reversal potential $V_{\text {PIC. }}$. The evolution of the activation variable $z_{\mathrm{PIC}}$ was governed by:

$$
\tau_{\mathrm{PIC}} \frac{d z_{\mathrm{PIC}}}{d t}=z_{\mathrm{PIC}}{ }^{s S}(V)-z_{\mathrm{PIC}}
$$

We adjusted $G_{l}^{S, D}$ and $V_{l}^{S, D}$ to guarantee that the resting potential of the soma and dendrites was the same $\left(V^{S}=V^{D}=0\right)$ and that the resting conductance (per unit area), $G_{l}^{S, D}+G_{h}^{S, D} \times z_{h}^{S S}(0)+G_{\mathrm{PIC}}^{S, D} \times z_{\mathrm{PIC}}^{S S}(0)$, took the same value, $G_{\text {rest }}$, everywhere. The space constant of the dendritic cable was then

$$
\lambda=\sqrt{d / 4 R_{i} G_{r e s t}},
$$

and its electrotonic length $\mathrm{L}=l / \lambda$.

Because the injected current distributes in the soma and in the dendrites, the admittance $Y(\omega)=1 / Z(\omega)$ of the motoneuron model is the sum of the admittances of the soma and of the dendrites. The admittance of the soma

$$
\begin{aligned}
Y^{S}(\omega)=G_{r e s t} S\left(1+i \omega \tau_{m}\right)- & G_{h}{ }^{S} S \frac{d z_{h}{ }^{S S}(0)}{d V} V_{h} \frac{1}{1+i \omega \tau_{h}} \\
& -G_{\mathrm{PIC}}{ }^{S} S \frac{d z_{\mathrm{PIC}}{ }^{S S}(0)}{d V} V_{\mathrm{PIC}} \frac{1}{1+i \omega \tau_{\mathrm{PIC}}},
\end{aligned}
$$

was computed by linearizing Equations 1-4 around the resting state and taking the Fourier transforms of the resulting equations. Because the contribution of $I_{\mathrm{h}}$ was determined not only by its contribution to the resting conductance $G_{\text {rest }}$ but also by its driving force $V_{\mathrm{h}}$ and by its propensity to deactivate during membrane depolarization, the strength of the somatic $I_{\mathrm{h}}$ is quantified by the dimensionless parameter $K_{h}^{S}=$ $\left(G_{h}^{S} / G_{\text {rest }}\right)\left(d z_{h}^{S S}(0) / d V\right) V_{\mathrm{h}}$. This parameter is negative because $I_{\mathrm{h}}$ opposes membrane depolarization. Similarly, the strength of the somatic PIC is quantified by $K_{\mathrm{PIC}}^{S}=\left(G_{\mathrm{PIC}}^{S} / G_{\text {rest }}\right)\left(d z_{\mathrm{PIC}}^{S S}(0) / d V\right) V_{\mathrm{PIC}}$, which is positive because membrane depolarization increases the activation of PICs.

A similar procedure yielded the admittance of the dendritic cable at its proximal end (Jack et al., 1983; Koch, 1984). Introducing the dimensionless parameters $K_{h}^{D}$ and $K_{\mathrm{PIC}}^{D}$, which are the dendritic equivalents of $K_{h}^{S}$ and $K_{\text {PIC }}^{S}$, we obtained

$$
Y^{D}(\omega)=G_{r e s t} \pi d \lambda q(\omega) \tanh (q(\omega) L)
$$

where

$$
q(\omega)=\sqrt{1+i \omega \tau_{m}-K_{h}^{D} / 1+i \omega \tau_{h}-K_{\mathrm{PIC}}^{D} / 1+i \omega \tau_{\mathrm{PIC}}} .
$$

The slope conductances, $G^{S}=G_{\text {rest }}^{S}\left(1-K_{h}^{S}-K_{\text {PIC }}^{S}\right)$ and

$$
G^{D}=G_{r e s t} \pi d \lambda \sqrt{1-K_{h}^{D}-K_{\mathrm{PIC}}{ }^{D}} \tanh \left(L \sqrt{1-K_{h}^{D}-K_{\mathrm{PIC}}^{D}}\right),
$$

of the soma and dendrites were obtained by setting $\omega$ to 0 in Equations 5 and 6.

If the current is injected in the dendrites, the voltage response of the soma is given by the transfer impedance of the model. Assuming uniform current injection and defining the transfer impedance as the ratio of the somatic depolarization to the current injected per space constant of dendrite, we obtained

$$
Z_{\text {trans }}(\omega)=\frac{R_{\infty}}{q^{2}(\omega)}\left(1-\frac{1}{\cosh (q(\omega) L)} \times \frac{Y^{S}(\omega)}{Y^{S}(\omega)+Y^{D}(\omega)}\right),
$$

where $R_{\infty}=1 / \pi d \lambda G_{\text {rest }}$ is the input resistance of a semi-infinite cable with membrane conductance $G_{\text {rest }}$.

In addition, we computed the sag produced by $I_{\mathrm{h}}$. In the absence of PICs, the sag ratio, $R$, is the ratio of the slope conductance of the motoneuron, $G^{S}+G^{D}$, which takes into account the deactivation of $I_{\mathrm{h}}$, to the resting conductance $G_{\text {rest }} S+G_{\text {rest }} \pi d \lambda \tanh (L)$, which does not take that deactivation into account. It follows that

$$
R=\frac{(1+\rho)\left(1-K_{h}^{S}\right)}{1+\rho\left(1-K_{h}^{S}\right) \tanh (L) / \sqrt{1-K_{h}^{D}} \tanh \left(L \sqrt{1-K_{h}^{D}}\right)},
$$

where the coefficient of dendritic dominance $\rho$ is the ratio $G^{D} / G^{S}$ of the input conductance of the dendrites at their proximal end to the input conductance of the soma alone. 


\section{Results}

Fast and slow PICs amplify EPSPs in different frequency bands

In a first step, we investigated how the amplification of EPSPs by PICs depended on their time course and on the kinetics of the PICs. We applied a series of sinusoidal stretches to the tendon of the TS while injecting an artificial PIC at the soma of a TS motoneuron. The frequency was increased from 1 to $25 \mathrm{~Hz}$ by steps of $1 \mathrm{~Hz}$ (Fig. 1). Because of the high dynamic sensitivity of muscle spindles, Ia afferents discharged at a higher rate (Fig. 1, inset) and more synchronously as the stretch frequency was increased. This was reflected in the time course of the EPSPs elicited in TS motoneurons, which changed from slowly varying, low-amplitude EPSPs at the lowest stretch frequencies to narrow, highamplitude EPSPs at the highest frequencies (Fig. $1 A_{1}$ ).

For the first stretch cycle $(1 \mathrm{~Hz})$, the peak-to-peak amplitude of the EPSP increased from $1.5 \mathrm{mV}$ in control condition (no PIC) to $2.0 \mathrm{mV}$ when a slow artificial PIC $\left(\bar{g}_{\text {PIC }}=\right.$ $100 \mathrm{nS}, \tau_{\mathrm{PIC}}=50 \mathrm{~ms}$ ) was added (Fig. $1 A_{2}$ ). The gain of the amplification, defined as the ratio of the EPSP amplitude in the presence of PIC to the control EPSP amplitude, was $\sim 1.4$. As shown in Figure $1 B$, it steadily declined as the frequency increased from 1 to $4 \mathrm{~Hz}$. Above $4 \mathrm{~Hz}$, EPSPs were barely amplified. In contrast, with a faster PIC $\left(\tau_{\text {PIC }}=10 \mathrm{~ms}\right.$ ) (Fig. $\left.1 A_{3}\right)$, the gain was $\sim 1.4$ over most of the frequency range, decreasing to 1.2 only above $20 \mathrm{~Hz}$. A still faster PIC $\left(\tau_{\text {PIC }}=1 \mathrm{~ms}\right.$ ) (Fig. $\left.1 A_{4}\right)$ amplified all EPSPs by $>1.5$. Interestingly, the maximum amplification (2.1) was reached for intermediate frequency stretches $\left(15 \mathrm{~Hz}\right.$ in this case) (Fig. $1 A_{4}$, arrow).

We recorded the responses of 10 TS motoneurons to sinusoidal stretches. In nine of them, artificial PICs with a time constant of $1 \mathrm{~ms}$ produced the maximal amplification at stretch frequencies between 7 and $15 \mathrm{~Hz}(12 \pm 3 \mathrm{~Hz})$. The maximal gain ranged from 1.3 to $3.2(2.1 \pm 0.6)$. In the 10 th motoneuron, the gain was $\sim 1.9$ at all frequencies. In contrast, for slow PICs, amplification was always maximal at the lowest frequency $(1 \mathrm{~Hz})$ and remained moderate. For $\tau_{\mathrm{PIC}}=100 \mathrm{~ms}$, it ranged from 1.1 to $1.4(1.2 \pm 0.1)$ in the 10 motoneurons. A $\tau_{\text {PIC }}$ of $50 \mathrm{~ms}$ was also tested in six of them, leading to similar results. The amplification at $1 \mathrm{~Hz}$ ranged from 1.2 to $1.4(1.3 \pm 0.1)$.

A slow PIC, mimicking a persistent calcium current, thus acts as a low gain and low-frequency amplifier. In contrast, a fast activating PIC, mimicking a persistent sodium current, operates over a broad frequency range and strongly amplifies the EPSPs elicited by stretches in the $7-15 \mathrm{~Hz}$ range.

The remainder of Results analyzes the mechanisms and the functional consequences of this differential amplification of in- puts by fast and slow PICs. We first show that most spinal motoneurons display a resonance attributable to the $I_{\mathrm{h}}$ current. We then investigate, in resonant motoneurons, how fast and slow PICs modify the resonance properties, and we study the consequences on the amplification of the dynamic and static components of Ia inputs elicited by ramp-and-hold muscle stretches. We then study the case of nonresonant motoneurons and show that input amplification by fast PIC then relies on plateau potentials. Finally, we show that, when both PICs operate together in a resonant motoneuron, the slow PIC may cancel the resonance, thus altering the way in which the fast PIC amplifies inputs.

\section{Most motoneurons display a subthreshold resonance}

To demonstrate the presence of a subthreshold resonance, we analyzed the voltage response to a ZAP current of time-varying frequency (see Materials and Methods) in 45 motoneurons [15 ABSm, 3 PBSt, 22 TS, 4 CP, 1 Tib, $G_{\text {in }}=0.8 \pm 0.3 \mu \mathrm{S}(0.4-1.8$ $\mu \mathrm{S})]$ and computed their FRC. A typical example is shown on Figure 2. A sine wave current with a $4 \mathrm{nA}$ peak-to-peak amplitude and a frequency increasing from 0 to $40 \mathrm{~Hz}$ in $10 \mathrm{~s}$ was injected into the motoneuron. The voltage followed the current variations, but its peak-to-peak modulations were not constant (Fig. $2 A)$. They increased from $4.0 \mathrm{mV}$ at low frequency to $4.6 \mathrm{mV}$ at $12 \mathrm{~Hz}$ and then decreased. Accordingly, the FRC displayed a maximum (Fig. $2 B$ ), which constitutes the very definition of a resonance. The impedance, $\sim 0.8 \mathrm{M} \Omega$ at $1 \mathrm{~Hz}$, steadily increased with the ZAP frequency until it approached $1.1 \mathrm{M} \Omega$ at the resonance frequency $f_{\mathrm{r}}=12 \mathrm{~Hz}$ (Fig. $2 \mathrm{~B}$, vertical line). Past this frequency, 
A

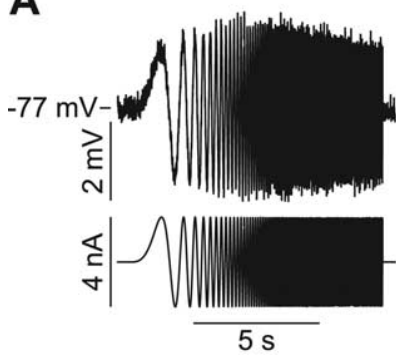

B

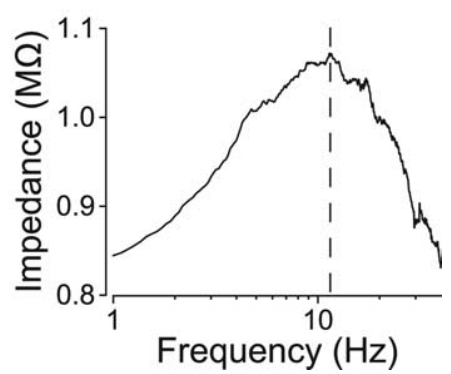

Figure 2. Subthreshold resonance in a motoneuron. $\boldsymbol{A}$, Voltage response (average of 4 recordings, top trace) to a ZAP current (bottom trace) of constant amplitude (4 nA peak-to-peak) and increasing frequency (from 0 to $40 \mathrm{~Hz}$; see Materials and Methods). $\boldsymbol{B}$, Impedance computed as the ratio of the fast Fourier transforms of voltage and current. Peak at $12 \mathrm{~Hz}$ indicates the resonance (dashed line). Same motoneuron as in Figure 1.

the impedance dropped rapidly because of passive filtering. In the motoneuron illustrated, the quality of the resonance was $Q=1.3$, which is in the same order of magnitude as reported in other types of neurons (Hutcheon et al., 1996). We observed a similar resonance in 39 motoneurons ( $87 \%$ of the sample), at a frequency ranging from 6 to $20 \mathrm{~Hz}(11 \pm 3 \mathrm{~Hz})$ and with a quality factor between 1.1 and $1.7(1.3 \pm 0.2)$. The six other neurons, which displayed no resonance, are analyzed in below (see Effects of PICs in nonresonant motoneurons).

\section{The subthreshold resonance is attributable to $I_{\mathrm{h}}$}

In motoneurons, the $I_{\mathrm{h}}$ current, which produces the sag in the voltage response to current steps (Ito and Oshima, 1965; Takahashi, 1990; McLarnon, 1995), is a very likely candidate to induce resonance, because it opposes voltage changes (Hutcheon and Yarom, 2000; Richardson et al., 2003). To test whether it is indeed responsible for the resonance, we applied intrathecally the selective blocker ZD-7288 (see Materials and Methods). We injected five small boluses $(\sim 200 \mu \mathrm{l})$ over the course of $4 \mathrm{~h}$. During that period, we determined the FRC of six motoneurons (four PBSt, two TS). The first three motoneurons, recorded 30-50 min after starting the drug injection, displayed a sag in response to hyperpolarizing current steps and a resonance in response to ZAP currents. In sharp contrast, the three following, recorded $70 \mathrm{~min}$ to $3 \mathrm{~h}$ after the start of the injection, exhibited no sag and their FRC showed no resonance. Given the small fraction of motoneurons that had no resonance in our control sample (13\%), the probability to record three consecutive nonresonant neurons by chance was very low (0.002). It is much more likely that the ZD-7288 took $>1 \mathrm{~h}$ to block the $I_{\mathrm{h}}$ current and to suppress the resonance.

To confirm the role of $I_{\mathrm{h}}$, we studied the voltage dependence of the resonance by shifting the membrane potential by direct current injection. As shown in Figure $3 A$, starting from a hyperpolarized level $(-80 \mathrm{mV})$, the quality factor decreased as the resting membrane potential became more and more depolarized (from 1.3 at $-80 \mathrm{mV}$ to 1.1 at $-60 \mathrm{mV}$ in the example shown). This trend was seen in 10 of the 12 motoneurons tested (Fig. $3 B$ ) and is consistent with the activation curve of the $I_{\mathrm{h}}$ current, which is only partially activated at the resting potential and is deactivated by membrane depolarization. Typically, the resonance was lost when the motoneuron was depolarized by $>10 \mathrm{mV}$. The voltage dependence of the resonance excludes that an outward current, such as $I_{\mathrm{M}}$, could be responsible for it. Indeed, the activation of this current with membrane depolarization would have increased the quality factor (Hu et al., 2002).

Last, we found that the quality factor was strongly correlated with the voltage sag in the population of 45 motoneurons in which the resonance was investigated $(r=0.80 ; p<0.001)$, as shown in Figure 4. In motoneurons with large sag, i.e., with large $I_{\mathrm{h}}$ current, the quality factor of the resonance was higher than in those with small sag. The six motoneurons without subthreshold resonance (open circles) also displayed little to no sag (sag ratio smaller than 1.2). They had a low input conductance $[0.5 \pm 0.2$ $\mu \mathrm{S}(0.4-1.0 \mu \mathrm{S}) ; n=6]$. Therefore, they were likely slow-type motoneurons, innervating slowly contracting muscle fibers (Burke, 1981) and presenting little $I_{\mathrm{h}}$ current (Gustafsson and Pinter, 1984).

\section{$I_{\mathrm{h}}$ must be localized in the dendrites to produce a resonance}

Motoneurons possess extensive dendritic trees that account for most of the membrane area. Their coefficient of dendritic dominance $\rho$ is estimated to be of the order of 10 (Fleshman et al., 1988). Dendrites thus account for $\sim 90 \%$ of the input conductance of motoneurons. Moreover, the electrotonic length of these dendrites, $l$, is estimated to be of the order of 1.5, which entails that motoneurons are not electrotonically compact. This raises the issue of whether the voltage sag and the membrane resonance observed in motoneurons are attributable to a somatic or to a dendritic $I_{\mathrm{h}}$ current. To investigate this question, we computed the sag ratio and the impedance curve of the motoneuron model described in Materials and Methods.

We first assumed that dendrites were passive, that the $I_{\mathrm{h}}$ current was restricted to the soma, and that no PIC was present in the soma and in the dendrites. When we set the strength $K_{h}^{S}$ of the somatic $I_{\mathrm{h}}$ to -0.5 , the impedance curve displayed a very weak resonance $(Q \approx 1.04)$ at $5 \mathrm{~Hz}$ (Fig. $5 A$, solid line), and the sag ratio at the soma was only $R=1.03$ (Fig. $5 B$, point a). This is because the somatic $I_{\mathrm{h}}$ current cannot counterbalance the current leak to the dendrites. When the somatic conductance $G_{h}^{S}$ was doubled, $R$ increased only to 1.05 . Actually, $R$ was always smaller than 1.1 for $\rho=10$. Thus, when dendrites are passive, the model shows little to no sag, and no clear resonance is observed.

This suggested that the dendrites must be endowed with a substantial $I_{\mathrm{h}}$ current. When $I_{\mathrm{h}}$ was put in both the soma and the dendrites of the model, the sag ratio grew with the ratio $G_{h}^{D} / G_{h}^{S}$ of the conductances of the dendritic and somatic components of $I_{\mathrm{h}}$, as shown in Figure $5 B$. When the somatic and dendritic $I_{\mathrm{h}}$ had the same conductance per unit area, the voltage sag measured at the soma was $\sim 1.3$ (Fig. $5 B$, point b), and the impedance curve displayed a clear resonance (Fig. $5 A$, dashed line). Doubling the conductance of the dendritic $I_{\mathrm{h}}$ current increased the sag ratio to 1.5 (Fig. $5 B$, point c), augmented the quality of the resonance by $17 \%$, and shifted $f_{\mathrm{r}}$ from 9.3 to $10.5 \mathrm{~Hz}$ (Fig. $5 A$, dash-dotted line). Suppressing the somatic $I_{\mathrm{h}}$ current had a lesser impact on the resonance, decreasing the quality factor and the resonant frequency by $<10 \%$ (Fig. $5 A$, dotted line d).

Experimental values of the sag ratio, of the resonance frequency, and of the quality factor $(1.4 \pm 0.2,11 \pm 3 \mathrm{~Hz}$, and $1.3 \pm$ 0.2 , respectively; $n=39$ ) are obtained in the model only if dendrites are endowed with enough $I_{\mathrm{h}}$ current. In addition, increasing the somatic $I_{\mathrm{h}}$ current has little effect on the sag ratio and the resonance of the model. This is in agreement with dynamicclamp experiments performed in five motoneurons, in which we added an artificial $I_{\mathrm{h}}$ current at the soma $\left(\theta_{h}=-90 \mathrm{mV}, \tau_{h}=100\right.$ $\mathrm{ms}, k_{h}=10 \mathrm{mV}, E_{h}=-30 \mathrm{mV}, \bar{g}_{h}=0.2-0.3 \mu \mathrm{S}$; same equations as those described in Materials and Methods for PICs). As predicted by the model, the artificial somatic $I_{\mathrm{h}}$ did not significantly modify the sag ratios ( $1.20 \pm 0.05$ vs $1.26 \pm 0.04 ; n=5 ; p=0.17$ ), 
the resonance frequencies ( $12 \pm 4$ vs $12 \pm 5 ; n=5 ; p=0.60)$, or the $Q$ factors $(1.2 \pm 0.1$ vs $1.2 \pm 0.1 ; n=5$; $p=0.68)$.

\section{Fast and slow PICs have opposite} effects on the resonance

What is the impact of PICs on the subthreshold resonance? We added an artificial PIC to 22 motoneurons, taken among the 39 that displayed a subthreshold resonance in the control condition. The PIC conductance was chosen in the 25-150 nS range (see Materials and Methods), and we varied its activation time constant from 1 to $100 \mathrm{~ms}$. The effects of such PICs are illustrated in Figure 6. Compared with the control response (Fig. 6 $6 A_{1}$ ), adding a slowly activating PIC $\left(\bar{g}_{\text {PIC }}=100\right.$ $\mathrm{nS} ; \tau_{\mathrm{PIC}}=50 \mathrm{~ms}$ ) induced a slight depolarization of the resting membrane potential and a visible amplification of the voltage response at low frequency (Fig. 6 $A_{2}$ ). The FRC changed from a curve peaked at the resonant frequency $\left(f_{\mathrm{r}}=12 \mathrm{~Hz}\right.$ ) (Fig. $6 \mathrm{~B}$, thin solid line) to an almost flat profile in the low-frequency region below $f_{\mathrm{r}}$ (dashed line). $Q$ decreased by $23 \%$, from 1.3 to 1.0. Adding the slowly activating PIC decreased the quality factor in 19 motoneurons of 22 . Reductions of $10-26 \%$ were seen in 11 of them, and the resonance was even abolished in six motoneurons. In average, $Q$ decreased significantly from $1.3 \pm 0.2$ in the control case to $1.2 \pm 0.2(1.0-1.7)(n=22$; paired Student's $t$ test, $p<0.0001)$.

Adding a fast PIC ( $\left.\tau_{\text {PIC }}=1 \mathrm{~ms}\right)$ had a totally different impact on the voltage response (Fig. $6 A_{4}$ ). All frequencies were amplified compared with control and particularly the intermediate frequencies (Fig. 6B, thick line). At $1 \mathrm{~Hz}$, the amplification was approximately the same as with a slow PIC (impedance of 1.1 $M \Omega$ ), but it increased rapidly with the frequency, the impedance reaching 1.6 $\mathrm{M} \Omega$ near the resonant frequency. The net effect of adding a fast activating PIC was to enhance the resonance. In the motoneuron illustrated, $Q$ increased by $16 \%$, from 1.3 to 1.5 . The enhancement was significant over the whole population tested, the quality factor increasing to $1.4 \pm 0.3(1.1-2.3)(n=22 ; p=$ $0.03)$. It increased by $>10 \%$ in 10 motoneurons and even reached $78 \%$ in one of them. In contrast, the average resonance frequency did not change significantly $(11 \pm 3 \mathrm{~Hz} ; n=22 ; p<0.001)$.

As the PIC time constant was varied between 1 and $100 \mathrm{~ms}$, we observed a smooth transition of the FRC between the two extreme cases presented above. For $\tau_{\text {PIC }}=10 \mathrm{~ms}$ (Fig. $6 A_{3}$ ), the FRC was the same as for $\tau_{\mathrm{PIC}}=1 \mathrm{~ms}$ for frequencies lower than 4 $\mathrm{Hz}$, but at higher frequencies it lied between the FRCs for $\tau_{\mathrm{PIC}}=$ $1 \mathrm{~ms}$ and $\tau_{\text {PIC }}=100 \mathrm{~ms}$ (Fig. $6 \mathrm{~B}$, dotted line). As such, two regimens could be distinguished: the faster PICs $\left(\tau_{\mathrm{PIC}}<20 \mathrm{~ms}\right)$ enhanced the resonance, whereas the slower PICs ( $\tau_{\text {PIC }} \geq 20 \mathrm{~ms}$ ) counteracted the effect of $I_{\mathrm{h}}$ and tended to cancel the resonance. These two amplification modes can be ascribed to persistent sodium currents (activation time constant $\sim 1-2 \mathrm{~ms}$ ) and calcium persistent currents (activation time constant larger than $20 \mathrm{~ms}$ ), respectively.

Can we understand the amplification of the EPSPs induced by muscle stretches in resonant motoneurons on the basis of their FRC? To answer this question, we compared the amplification of
B

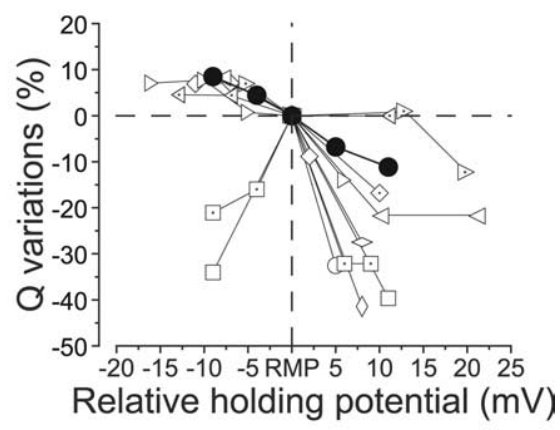

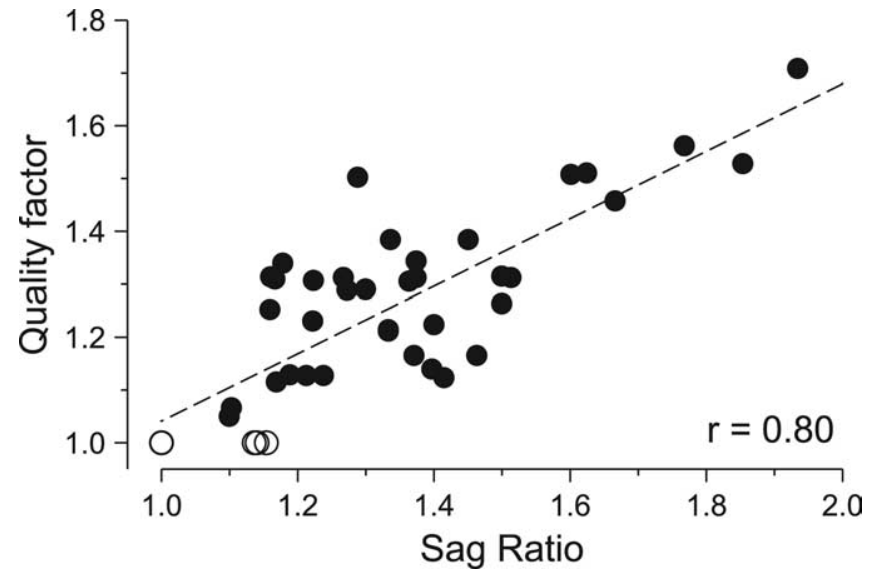

Figure 4. Resonance quality was linearly correlated to sag ratio. Quality factor against sag ratio for 45 motoneurons. Dashed line, Best linear fit. Open circles, The six motoneurons without resonance.

EPSPs with the impedance changes that PICs elicited in nine motoneurons, in which we performed both ZAPs and muscle stretches protocols. We characterized the frequency dependence of the amplification of sinusoidal currents by the ratio of the impedance with PIC to the impedance without PIC. As shown in Figure $6 C$, the amplification of sinusoidal currents displayed striking similarities with the amplification of EPSPs elicited by sinusoidal muscle stretches (Fig. $1 B$ ). In both cases, a slow PIC increased the gain in the low-frequency region, whereas a fast PIC increased the gain over the whole frequency range but preferentially around the resonance frequency. The response to an input of given frequency was proportional to that input and to the impedance at that frequency, in accordance with Ohm's law.

\section{Dendritic PICs have similar effects on the resonance as somatic PICs}

We examined in the motoneuron model whether the dendritic component of PICs had a similar effect on the impedance as the somatic component. Current was uniformly injected all along the dendritic cable, and we computed how the transfer impedance from the dendrite to the soma was modified by a dendritic PIC. 

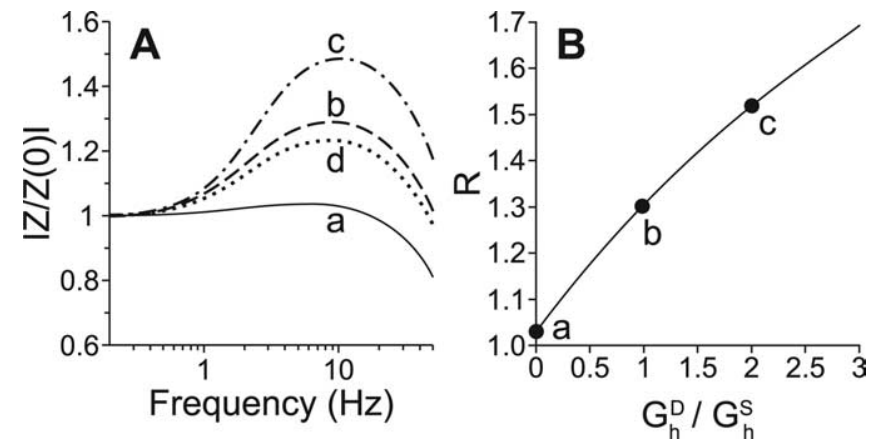

Figure 5. Modeling the impact of the dendritic $l_{\mathrm{h}}$ current on the resonance properties. $A, \mathrm{FRC}$ curve (semilogarithmic scale). The modulus of the impedance (IZI) is normalized to 1 at zero frequency. It is shown for four distributions of $l_{h}$ in the soma and dendrites: $a$, Passive dendrites (with 5 ms time constant), somatic $I_{\mathrm{h}}$ of strength $K_{h}^{S}=-0.5$, and activation time constant $\tau_{h}$ $=100 \mathrm{~ms}$ (solid line). b, Same conductance of the $I_{\mathrm{h}}$ current in the soma and in the dendrites $\left(K_{h}^{S}\right.$

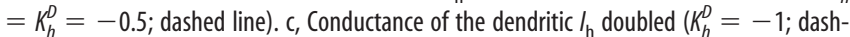
dotted line). d, No somatic $I_{\mathrm{h}}\left(K_{h}^{S}=0, K_{h}^{D}=-0.5\right.$; dotted line). $\boldsymbol{B}$, The sag ratio at the soma, $R$, is displayed against the ratio of the dendritic and somatic conductances of the $I_{\mathrm{h}}$ current. The black dots labeled from a to c correspond the first three distributions of $I_{h}$ considered in $\boldsymbol{A}$.
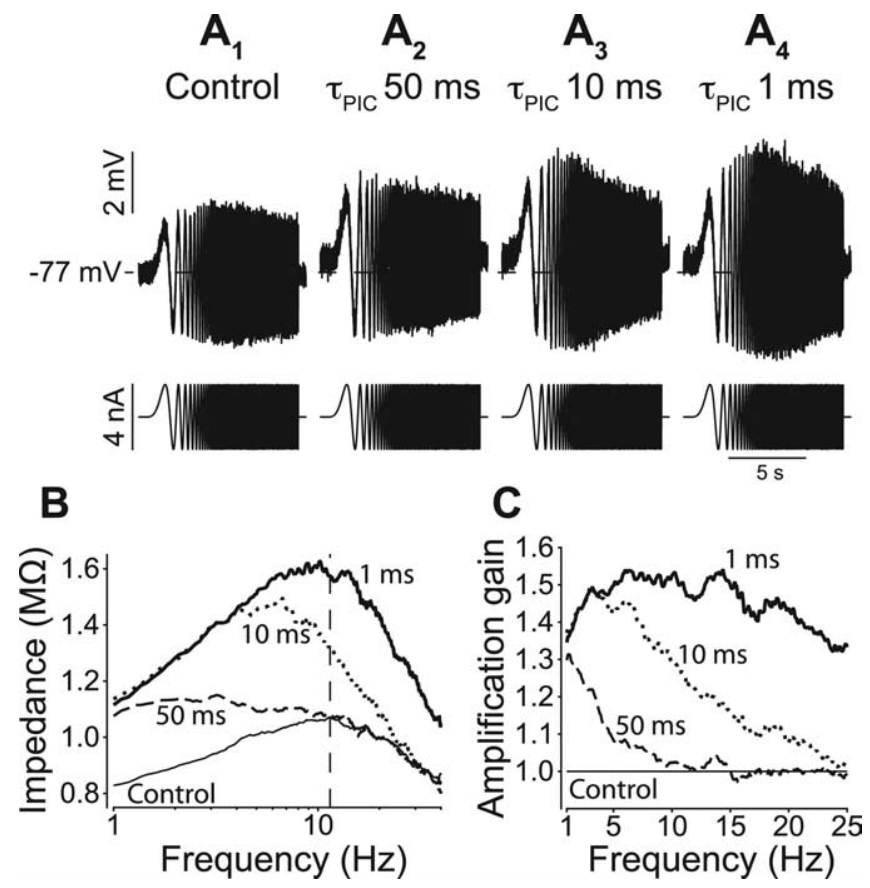

Figure 6. Changes in FRC elicited by artificial PICS. $A_{1}-A_{4}$, Bottom, ZAP. Top, Voltage (average of 3-4 records). Dashed line, Resting potential in control condition. $B$, Control FRC (thin solid line) and FRC with PIC. $\tau_{\text {PIC }}=1 \mathrm{~ms}$ (thick solid line), $10 \mathrm{~ms}$ (dotted line), or $50 \mathrm{~ms}$ (dashed line). C, Amplification gain against frequency (ratio of FRC with PIC to control FRC). Same symbols as in $\boldsymbol{B}$. Horizontal line indicates no amplification. Same motoneuron as in Figures 1 and 2 .

The transfer impedance is plotted in Figure 7 in control condition (no PIC), and with fast PIC or slow PIC added. A fast PIC $\left(\tau_{\text {PIC }}=1 \mathrm{~ms}\right)$ of same strength as the dendritic $I_{\mathrm{h}}$ current $\left(K_{\mathrm{PIC}}^{D}=\right.$ 0.5 ) increased the impedance over the whole frequency range displayed, and the quality factor of the resonance augmented by $20 \%$ (dashed line) compared with control (solid line). In contrast, a slow PIC $\left(\tau_{\mathrm{PIC}}=100 \mathrm{~ms}\right)$ of the same strength increased the impedance below $10 \mathrm{~Hz}$ and canceled the resonance $\left(K_{\mathrm{PIC}}^{D}=\right.$ 0.5) (dash-dotted line). The impedance was then the same as for a passive membrane. This is because the slow PIC compensates exactly the effect of the $I_{\mathrm{h}}$ current on the dendritic admittance.

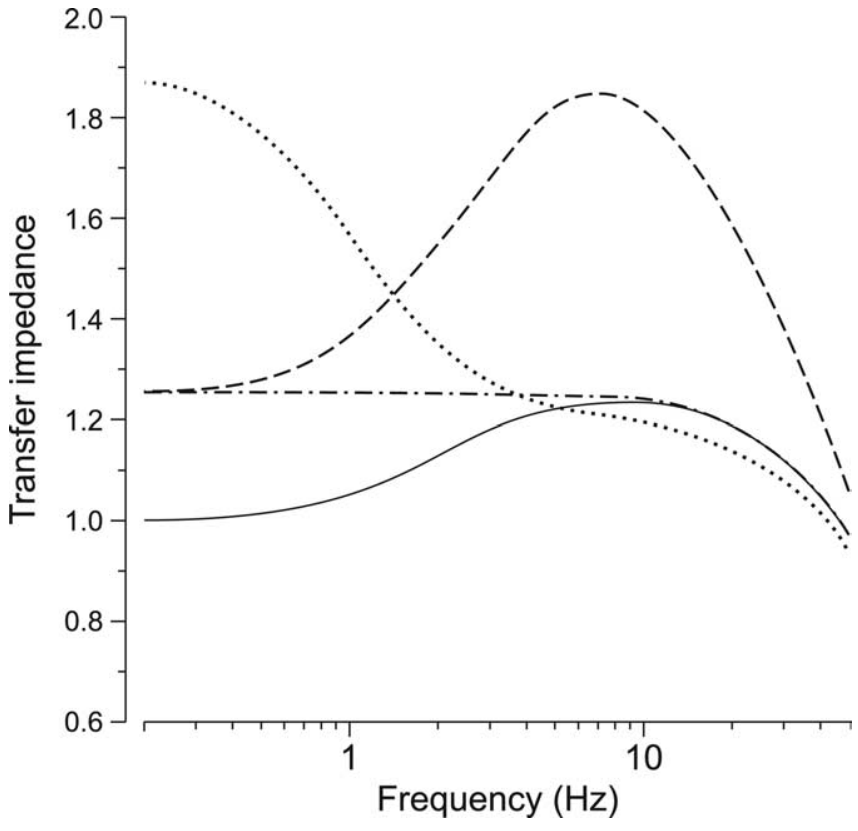

Figure 7. Impact of dendritic PICs on the transfer impedance from the dendrite to the soma in the motoneuron model. The transfer impedance $\left(Z_{\text {trans }}\right)$ is plotted against the frequency: control (no PIC, $K_{h}^{S}=0, K_{h}^{D}=-0.5$; solid line), fast PIC $\left(\tau_{\mathrm{PIC}}=1 \mathrm{~ms}, K_{\mathrm{PIC}}^{D}=0.5 ;\right.$ dashed line), slow PIC $\left(\tau_{\mathrm{PIC}}=100 \mathrm{~ms}\right)$ of same strength $\left(K_{\mathrm{PIC}}^{D}=0.5\right.$; dash-dotted line), and doubled strength $\left(K_{\mathrm{PIC}}^{D}=1\right.$; dotted line).

When the conductance of the slow PIC was doubled, the transfer impedance was strongly increased at very low frequency, and the impedance curve decreased monotonically as the frequency increases (dotted line).

This shows that dendritic PICs have the same effects on the resonance as somatic PICs. These effects are quite substantial when the intensity of the PIC is comparable with the intensity of the $I_{\mathrm{h}}$ current. These results suggest that both the somatic and dendritic components of PICs affect the resonance properties of motoneurons.

Consequences for the amplification of the dynamic and static components of Ia inputs in resonant motoneurons

Spindle primary endings exhibit a high dynamic sensitivity to stretches (Matthews, 1964). Accordingly, muscle stretches produce a complex input to motoneurons, displaying both dynamic and static components. We used ramp-and-hold protocols (see Materials and Methods) to separate these two components of the voltage response and to study how each of them was amplified by PICs.

Experiments were performed in 11 resonant TS motoneurons $\left[G_{\text {in }}=0.9 \pm 0.3 \mu \mathrm{S}(0.5-1.4 \mu \mathrm{S})\right]$. A typical example is shown in Figure 8. In the control response (without PIC) to a $10 \mathrm{~mm} / \mathrm{s}$ stretch, the dynamic and static components had respective amplitudes of 3.9 and $0.9 \mathrm{mV}$ (Fig. $\left.8 A_{1}\right)$. A fast PIC $\left(\bar{g}_{\mathrm{PIC}}=100 \mathrm{nS}\right.$; $\tau_{\text {PIC }}=1 \mathrm{~ms}$ ) (Fig. $8 A_{2}$ ) strongly amplified the dynamic component, which increased to $12.6 \mathrm{mV}$, more than thrice the control amplitude. The static component was much less amplified, increasing only to $1.5 \mathrm{mV}, 1.7$ times the control response. In contrast, a slow PIC $\left(\tau_{\text {PIC }}=50 \mathrm{~ms}\right.$ ) (Fig. $\left.8 A_{3}\right)$ amplified the dynamic component by only 1.6 , barely more than the static component (1.4). Figure $8 B$ shows how the amplification of the dynamic and static components depended on the PIC time constant. The static component was amplified by $\sim 1.5$, regardless of $\tau_{\mathrm{PIC}}$. In sharp contrast, the dynamic component was less and less amplified as 


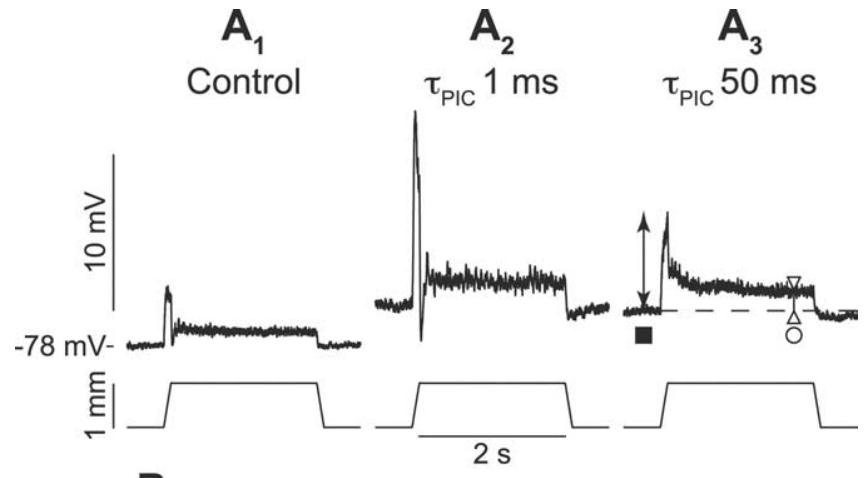

B

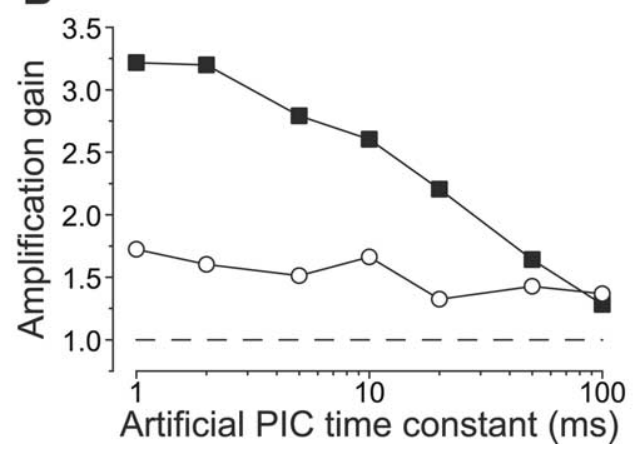

Figure 8. Differential amplification of dynamic and static components of la input elicited by a ramp-and-hold stretch. $A_{1}-A_{3}$, Bottom, Muscle length. Top, EPSPs (average of $3-4$ records) in control condition (no PIC, $A_{1}$ ) and with a fast $\left(A_{2}\right)$ or a slow $\left(A_{3}\right)$ PIC. Dynamic response measured by the peak amplitude (filled arrow). Static response measured by average amplitude over the last $500 \mathrm{~ms}$ of holding (open arrow). $\boldsymbol{B}$, Amplification of dynamic (filled squares) and static (open circles) components against $\tau_{\mathrm{PIC}}$. TS motoneuron; $G_{\text {in }}=1.0 \mu \mathrm{S}$; conduction velocity, $90 \mathrm{~m} / \mathrm{s}$ (probably fast type).

$\tau_{\text {PIC }}$ was increased. For time constants larger than $50 \mathrm{~ms}$, dynamic and static components were amplified in the same way. Similar results were obtained in the 11 motoneurons investigated. Fast PICs $\left(\tau_{\text {PIC }}=1 \mathrm{~ms}\right)$ preferentially affected the dynamic component of the Ia input, which was amplified 1.2-3.4 times more than the static component (mean $1.9 \pm 0.6 ; n=11 ; p=0.0004$ ).

\section{Effects of PICs in nonresonant motoneurons}

We tested the effect of PICs on four of the six motoneurons that displayed no resonance. As illustrated in Figure 9, the amplification at low frequency increased as the time constant of the PIC decreased $\left(\bar{g}_{\text {PIC }}=100 \mathrm{nS}\right.$ ) (Fig. 9A,B). The same result was obtained in the four nonresonant motoneurons. This is the opposite of what we observed in resonant motoneurons (Fig. 6B), in which decreasing the PIC time constant did not affect the gain at low frequency. This strong amplification at low frequency results from a substantial activation of the PIC in nonresonant motoneurons, although we used the same relative PIC conductance $\left(\bar{g}_{\text {PIC }} / G_{\text {in }}, 0.13 \pm 0.06 ; n=4\right)$ as in the resonant ones $(0.11 \pm 0.04$; $n=22)$.

This had a drastic impact on the response to ramp-and-hold stretches. The motoneuron illustrated in Figure $9 C$ is the only nonresonant motoneurons in which we could record responses to ramp-and-hold stretches. A fast PIC $\left(\tau_{\text {PIC }}=1 \mathrm{~ms}\right)$ with a conductance of $25 \mathrm{nS}$ (Fig. 9 $C_{2}$ ) amplified only moderately the dynamic component to $23.2 \mathrm{mV}$ (gain of 1.4). On the falling phase of the dynamic response, a hump (arrow) was visible, because PIC activation outlasted the dynamic component. When the maximal conductance was increased to $50 \mathrm{nS}$ (Fig. $9 C_{3}$ ), the amplification of the dynamic component was almost the same. However, the dynamic component triggered a plateau potential that persisted throughout the hold phase and disappeared only when the muscle was shortened back. This plateau potential led to a strong amplification of the static component (from 3.3 to $17.8 \mathrm{mV}$ ). It stemmed from the activation of the voltagedependent PICs that could not be counterbalanced by the $I_{\mathrm{h}}$ current in these nonresonant motoneurons.

\section{Resonant amplification or not? The action of the fast PIC depends on whether or not the resonance is abolished by the slow PIC}

In three resonant motoneurons, we could add simultaneously a fast and a slow artificial PIC. The impact of the fast PIC was modified by the slow PIC, as shown in Figure 10. In this TS motoneuron, a slow PIC alone $\left(\tau_{\mathrm{PIC}}=100 \mathrm{~ms}\right)$ with a conductance of $150 \mathrm{nS}$ abolished the resonance (Fig. $10 A_{2}, B$, dashed line), whereas a fast PIC alone $\left(\tau_{\text {PIC }}=1 \mathrm{~ms}, \bar{g}_{\text {PIC }}=50 \mathrm{nS}\right)$ enhanced it (Fig. $10 A_{3}, B$, dotted line). When both fast and slow PICs were added, the maximal amplification no longer occurred at the resonant frequency. The FRC had the same shape as when the slow PIC was acting alone but was shifted upward. The maximal effect was observed at low frequencies. At $1 \mathrm{~Hz}$, the amplification factor was 1.7 when both PICs were present compared with 1.3 when the fast PIC was acting alone. We obtained similar results in the two other motoneurons. This suggests that the fast PIC amplify preferentially inputs either around the resonant frequency or at low frequency, depending on whether or not the resonance is canceled by the slow PIC.

These modifications of the FRC had a strong impact on the processing of Ia inputs elicited by a ramp-and-hold stretches. Alone, the slow PIC (Fig. 10C 2 ) moderately amplified the dynamic and static components of the response with respect to control (1.4 and 1.3, respectively). The fast PIC (Fig. 10C $_{3}$ ) strongly amplified the dynamic component (2.2) but not the static component. When both PICs were present (Fig. 10C 4 ), the amplification of the dynamic component was little affected (2.1), but an aborted plateau potential was observed during the static response (arrow), which was substantially enhanced. Similar results were obtained in another motoneuron. This indicates that the slow PIC can switch EPSP amplification by fast PICs from a preferential amplification of the dynamic component to a mode in which the static component is also amplified because of the apparition of plateau potentials.

\section{Discussion}

We show that most motoneurons display a subthreshold resonance attributable to the $I_{\mathrm{h}}$ current. In resonant motoneurons, PICs do not elicit plateau potentials, and the amplification of synaptic inputs is determined by changes of the membrane impedance. A slow PIC, mimicking $I_{\mathrm{CaL}}$, amplifies EPSPs by increasing the impedance at low frequency, reducing the resonance. In sharp contrast, a fast PIC, mimicking $I_{\mathrm{NaP}}$, acts as a broadband amplifier with higher gain near the resonance frequency. It amplifies the dynamic component of the Ia input more than the static response. In nonresonant motoneurons, which innervate slow contracting muscle fibers and are deprived of $I_{\mathrm{h}}$ current, the fast PIC can trigger plateau potentials. These plateau potentials, sustained by the persistent activation of both $I_{\mathrm{NaP}}$ and $I_{\mathrm{CaL}}$, amplify the static response more than the dynamic one. This also occurs in motoneurons that innervate fast contracting muscle fibers when the slow PIC is strong enough to abolish the resonance. 

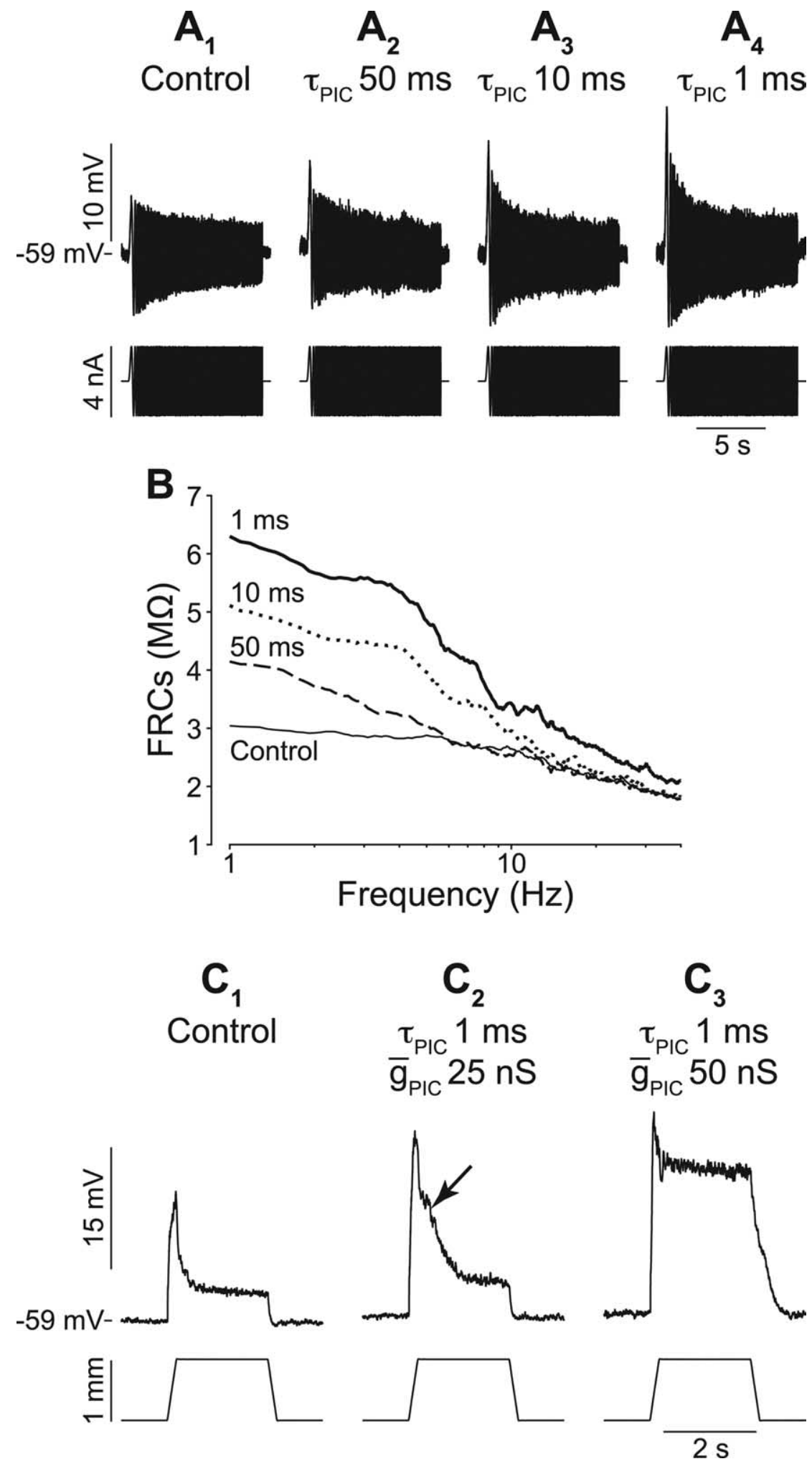

Figure 9. Input amplification in nonresonant motoneurons. $\boldsymbol{A}_{1}-\boldsymbol{A}_{4}$, Bottom, ZAP. Top, Voltage (average of 3 records). $\bar{g}_{\mathrm{PIC}}=50 \mathrm{nS} . \boldsymbol{B}$, FRC without PIC (thin solid line) and with PIC. $\tau_{\text {PIC }}=1 \mathrm{~ms}$ (thick solid line), $10 \mathrm{~ms}$ (dotted line), or $50 \mathrm{~ms}$ (dashed line). $C_{1}-C_{3}$, Bottom, Muscle length. Top, EPSPs without PIC $\left(\boldsymbol{C}_{1}\right)$, with fast PIC (1 ms), $\bar{g}_{\text {PIC }}=25 \mathrm{nS}\left(\boldsymbol{C}_{2}\right)$ or $50 \mathrm{nS}\left(\boldsymbol{C}_{3}\right)$. Average of three to five recordings. Note aborted plateau potential in $C_{2}$ (arrow). TS motoneuron $\left(G_{\text {in }}=0.4 \mu S\right.$ ) with no $I_{h}$ current (neither sag nor resonance, probably slow type).

\section{Resonance and $I_{\mathrm{h}}$ current}

We report for the first time a subthreshold resonance in mammalian spinal motoneurons and provide evidence that $I_{\mathrm{h}}$ underlies this resonance, as in many types of neurons (Hutcheon et al.,
1996; Nguyen et al., 2004; Wu et al., 2005). (1) One hour after the application of a selective $I_{\mathrm{h}}$ blocker $(\mathrm{ZD}-$ 7288), we found no motoneuron displaying a subthreshold resonance. (2) Motoneurons without sag did not exhibit a resonance. (3) The quality factor of the resonance was linearly correlated to the sag ratio, which quantifies the impact of $I_{\mathrm{h}}$ on the voltage response. (4) The resonance diminished or was even abolished when the membrane was depolarized. In contrast, it tended to increase when the potential was hyperpolarized.

Study of a simple model of motoneuron suggests that most of the $I_{\mathrm{h}}$ current is located in the dendrites. An $I_{\mathrm{h}}$ conductance restricted to the soma of the model is unable to counterbalance the strong dendritic leak and produces insignificant sag and resonance. In contrast, when the $I_{\mathrm{h}}$ current is distributed all over the dendrites, the model displays sag ratios, resonance frequencies, and quality factors comparable with the experimental data. This is in keeping with a recent immunocytochemical study demonstrating that the HCN channels mediating the $I_{\mathrm{h}}$ current are located not only at the soma but are also widely distributed in dendrites (Milligan et al., 2006).

In our experiments, QX-314 did not block the $I_{\mathrm{h}}$ current. All 26 motoneurons recorded using microelectrodes filled with QX-314 exhibited a slow sag in response to current pulses and a rebound at the pulse offset. Moreover, these motoneurons and the 13 resonant motoneurons recorded without QX-314 displayed no significant difference in their sag ratios $[1.4 \pm 0.2(1.1-1.9)$ vs $1.3 \pm 0.1(1.1-1.6)]$, their quality factors $[1.3 \pm 0.2(1.1-1.7)$ vs $1.3 \pm$ $0.2(1.1-1.6)]$, and their resonance frequencies $[11 \pm 3 \mathrm{~Hz}(6-16 \mathrm{~Hz})$ vs $12 \pm 3 \mathrm{~Hz}(8-19 \mathrm{~Hz})$; all $p>0.2$. We also remark that the six motoneurons that displayed little to no sag, and accordingly no resonance, were recorded without QX-314. These results are in sharp contrast with those obtained in hippocampal (Perkins and Wong, 1995) and neocortical (Hwa and Avoli, 1991) cells in which QX-314 was shown to block $I_{\mathrm{h}}$. The difference between motoneurons and those other cells might stem from a limited diffusion of QX-314 in the dendrites of motoneurons or the involvement of different HCN channels (Santoro et al., 2000; Kaupp and Seifert, 2001). 


\section{Effect of an artificial PIC}

When cats are anesthetized with barbiturates, natural PICs are strongly depressed. Plateau potential or hysteresis of the $I-f$ curve have never been reported in such conditions, and the $I-V$ curves recorded in voltage clamp did not reveal the presence of PICs (Kuo et al., 2003, their Fig. 1B). This is likely attributable to the very low level of neuromodulation in this state (Lee and Heckman, 2000) and to the blockade of L-type channels by barbiturates (Guertin and Hounsgaard, 1999). Furthermore, the QX-314 used in a large number of motoneurons effectively suppressed $I_{\mathrm{NaP}}$ and contributed to block $I_{\mathrm{CaL}}$ (Lee and Heckman, 1999).

The natural PICs were replaced by dynamic clamp-induced artificial PICs. We did not attempt to model with precision the sodium and calcium PICs. Indeed, their characteristics are essentially unknown. In particular, disagreements persist on the kinetics of $I_{\mathrm{CaL}}$. Although many authors agree that it is slow (with an activation time constant of a few tens of milliseconds) (Carlin et al., 2000; Mermelstein et al., 2000; Li and Bennett, 2003), studies in recombinant cells suggest that its kinetics might be much faster (2-3 ms) (Helton et al., 2005). These discrepancies might be attributable to a great diversity in the properties of these channels, related in particular to their subunit composition (Lipscombe et al., 2002). In this work, we varied the PIC time constant over a large range, from 1 to $100 \mathrm{~ms}$, to cover all these situations.

In resonant motoneurons, Ia EPSPs amplification could be accounted for by the impedance changes caused by PICs. Whatever the PIC kinetics, only the amplitude of EPSPs was affected and not their time course. This is in keeping with experiments performed in decerebrate cats: when PICs were moderately activated, excitatory inputs arising during sinusoidal muscle stretches were amplified, but their time course were not altered (Bennett et al., 1998, their Fig. 6). In nonresonant motoneurons, the amplifications could not be accounted for by impedance changes: the same artificial PICs as used in resonant motoneurons triggered a plateau potential.

The persistent sodium and calcium currents are both present in spinal motoneurons (Hsiao et al., 1998; Li and Bennett, 2003; Powers and Binder, 2003) and have comparable magnitudes (Harvey et al., 2006a). Our results show that the response to synaptic input depends on the balance between $I_{\mathrm{h}}$ that creates the resonance, $I_{\mathrm{CaL}}$ that tends to suppress it, and $I_{\mathrm{NaP}}$ that enhances it. The effect of $I_{\mathrm{NaP}}$ thus depends on the strength of $I_{\mathrm{CaL}}$. If $I_{\mathrm{CaL}}$ is too weak to compensate the $I_{\mathrm{h}}$ current, the resonance persists and is amplified by $I_{\mathrm{NaP}}$. In contrast, when the resonance is abolished by $I_{\mathrm{CaL}}, I_{\mathrm{NaP}}$ amplifies the low-frequency response and tends to trigger plateau potentials. Monoaminergic neuromodulation strongly increases both $I_{\mathrm{CaL}}$ (Lee and Heckman, 2000) and $I_{\mathrm{NaP}}$ (Harvey et al., 2006b,c) and may thereby switch the motoneuron from a resonant to a nonresonant mode of amplification. This might partly account for the spasticity after spinal lesions. After a chronic spinalization, it was shown that PICs of rat motoneurons become hypersensitive to monoamines (Harvey et al., 2006b,c). They are then strongly facilitated and will produce plateau potentials responsible for long-lasting reflexes and muscle spasms (Li et al., 2004).

In our experiments, we imposed PICs by dynamic clamp at the soma. However, electrophysiological and immunohistochemical evidence indicate that fast and slow PICs have a dendritic com- 
ponent (Hounsgaard and Kiehn, 1993; Bennett et al., 1998; Carlin et al., 2000; Lee and Heckman, 2000; Ballou et al., 2006; Jones and Lee, 2006). Study of a motoneuron model suggests that dendritic PICs also interact with the $I_{\mathrm{h}}$ current and amplify synaptic inputs in the same way as somatic PICs.

\section{Impact of the differential amplification on motoneuron recruitment}

Interestingly, the motoneurons endowed with substantial $I_{\mathrm{h}}$ and displaying a resonance innervate fast contracting motor units developing a large force, either fatigable (FF type) or fatigue resistant (FR type). Fast PICs can strongly amplify transient EPSPs to these motoneurons and bring them to their spiking threshold. Fast PICs thus lower the recruitment threshold of FR and FF motoneurons. This increases the overall input-output gain of the motoneuron pool (Heckman, 1994) and helps to produce fast and strong contractions. One might speculate that fast PICs amplify transient descending commands in fast types motoneurons to produce "ballistic" movements. In addition, our work suggest that, during a rapid muscle stretch, e.g., during a loss of balance, the amplification of dynamic Ia component in motoneurons will help to regain ones equilibrium. Fast PICs thus seem to have the same overall effect as the dynamic $\gamma$-motoneurons, which augments the dynamic sensitivity of primary endings and the dynamic component of the proprioceptive feedback to motoneurons (Crowe and Matthews, 1964; Emonet-Denand et al., 1975; Emonet-Denand et al., 1977).

Our study also suggests that, in slow-type motoneurons, the dynamic component elicited by the ramp stretch easily triggers a plateau potential that persists throughout the hold phase. This leads to a strong amplification of the static component. This effect is reminiscent of the action of static fusimotor axons (Emonet-Denand et al., 1977) on primary endings and might help slow motoneurons to discharge during sustained stretches. Because the $\mathrm{S}$ motor units are resistant to fatigue, the resulting sustained contraction might contribute to maintain posture. We may also speculate that, when $I_{\mathrm{CaL}}$ becomes strong enough to abolish the resonance of FR motoneurons, plateau potentials will be triggered, and FR motor units will contribute more efficiently to posture.

\section{References}

Ballou EW, Smith WB, Anelli R, Heckman CJ (2006) Measuring dendritic distribution of membrane proteins. J Neurosci Methods 156:257-266.

Bennett DJ, Hultborn H, Fedirchuk B, Gorassini M (1998) Synaptic activation of plateaus in hindlimb motoneurons of decerebrate cats. J Neurophysiol 80:2023-2037.

Brizzi L, Meunier C, Zytnicki D, Donnet M, Hansel D, Lamotte d'Incamps B, Van Vreeswijk C (2004) How shunting inhibition affects the discharge of lumbar motoneurones: a dynamic clamp study in anaesthetized cats. J Physiol (Lond) 558:671-683.

Burke RE (1981) Motor units: anatomy, physiology and functional organization. In: Handbook of physiology (Brooks VB, ed), pp 345-422. Baltimore: Williams and Wilkins.

Carlin KP, Jones KE, Jiang Z, Jordan LM, Brownstone RM (2000) Dendritic L-type calcium currents in mouse spinal motoneurons: implications for bistability. Eur J Neurosci 12:1635-1646.

Chevallier S, Nagy F, Cabelguen JM (2006) Cholinergic control of excitability of spinal motoneurones in the salamander. J Physiol (Lond) 570:525-540.

Conway BA, Hultborn H, Kiehn O, Mintz I (1988) Plateau potentials in alpha-motoneurones induced by intravenous injection of L-dopa and clonidine in the spinal cat. J Physiol (Lond) 405:369-384.

Crill WE (1996) Persistent sodium current in mammalian central neurons. Annu Rev Physiol 58:349-362.

Crowe A, Matthews PB (1964) The effects of stimulation of static and dy- namic fusimotor fibres on the response to stretching of the primary endings of muscle spindles. J Physiol (Lond) 174:109-131.

D’Angelo E, De Filippi G, Rossi P, Taglietti V (1998) Ionic mechanism of electroresponsiveness in cerebellar granule cells implicates the action of a persistent sodium current. J Neurophysiol 80:493-503.

Emonet-Denand F, Jami L, Laporte Y (1975) Skeleto-fusimotor axons in the hind-limb muscles of the cat. J Physiol (Lond) 249:153-166.

Emonet-Denand F, Laporte Y, Matthews PB, Petit J (1977) On the subdivision of static and dynamic fusimotor actions on the primary ending of the cat muscle spindle. J Physiol (Lond) 268:827-861.

Fetz EE, Jankowska E, Johannisson T, Lipski J (1979) Autogenetic inhibition of motoneurones by impulses in group Ia muscle spindle afferents. J Physiol (Lond) 293:173-195.

Fleshman JW, Segev I, Burke RB (1988) Electrotonic architecture of typeidentified alpha-motoneurons in the cat spinal cord. J Neurophysiol 60:60-85.

Guertin PA, Hounsgaard J (1999) Non-volatile general anaesthetics reduce spinal activity by suppressing plateau potentials. Neuroscience 88:353-358.

Gustafsson B, Pinter MJ (1984) An investigation of threshold properties among cat spinal alpha-motoneurones. J Physiol (Lond) 357:453-483.

Gutfreund Y, Yarom Y, Segev I (1995) Subthreshold oscillations and resonant frequency in guinea-pig cortical neurons: physiology and modelling. J Physiol (Lond) 483:621-640.

Harris NC, Constanti A (1995) Mechanism of block by ZD 7288 of the hyperpolarization-activated inward rectifying current in guinea pig substantia nigra neurons in vitro. J Neurophysiol 74:2366-2378.

Harvey PJ, Li Y, Li X, Bennett DJ (2006a) Persistent sodium currents and repetitive firing in motoneurons of the sacrocaudal spinal cord of adult rats. J Neurophysiol 96:1141-1157.

Harvey PJ, Li X, Li Y, Bennett DJ (2006b) 5-HT2 receptor activation facilitates a persistent sodium current and repetitive firing in spinal motoneurons of rats with and without chronic spinal cord injury. J Neurophysiol 96:1158-1170.

Harvey PJ, Li X, Li Y, Bennett DJ (2006c) Endogenous monoamine receptor activation is essential for enabling persistent sodium currents and repetitive firing in rat spinal motoneurons. J Neurophysiol 96:1171-1186.

Heckman CJ (1994) Computer simulations of the effects of different synaptic input systems on the steady-state input-output structure of the motoneuron pool. J Neurophysiol 71:1727-1739.

Helton TD, Xu W, Lipscombe D (2005) Neuronal L-type calcium channels open quickly and are inhibited slowly. J Neurosci 25:10247-10251.

Hounsgaard J, Kiehn O (1993) Calcium spikes and calcium plateaux evoked by differential polarization in dendrites of turtle motoneurones in vitro. J Physiol (Lond) 468:245-259.

Hounsgaard J, Mintz I (1988) Calcium conductance and firing properties of spinal motoneurones in the turtle. J Physiol (Lond) 398:591-603.

Hsiao CF, Del Negro CA, Trueblood PR, Chandler SH (1998) Ionic basis for serotonin-induced bistable membrane properties in guinea pig trigeminal motoneurons. J Neurophysiol 79:2847-2856.

Hu H, Vervaeke K, Storm JF (2002) Two forms of electrical resonance at theta frequencies, generated by $\mathrm{M}$-current, $\mathrm{h}$-current and persistent $\mathrm{Na}^{+}$ current in rat hippocampal pyramidal cells. J Physiol (Lond) 545:783-805.

Hultborn H, Denton ME, Wienecke J, Nielsen JB (2003) Variable amplification of synaptic input to cat spinal motoneurones by dendritic persistent inward current. J Physiol (Lond) 552:945-952.

Hutcheon B, Yarom Y (2000) Resonance, oscillation and the intrinsic frequency preferences of neurons. Trends Neurosci 23:216-222.

Hutcheon B, Miura RM, Puil E (1996) Subthreshold membrane resonance in neocortical neurons. J Neurophysiol 76:683-697.

Hwa GG, Avoli M (1991) Hyperpolarizing inward rectification in rat neocortical neurons located in the superficial layers. Neurosci Lett 124:65-68.

Ito M, Oshima T (1965) Electrical behaviour of the motoneurone membrane during intracellularly applied current steps. J Physiol (Lond) 180:607-635.

Jack JB, Noble D, Tsien RW (1983) Electrical current flow in excitable cells, Ed 2. Oxford: Oxford UP.

Jones SM, Lee RH (2006) Fast amplification of dynamic synaptic inputs in spinal motoneurons in vivo. J Neurophysiol 96:2200-2206. 
Kaupp UB, Seifert R (2001) Molecular diversity of pacemaker ion channels. Annu Rev Physiol 63:235-257.

Kay AR, Sugimori M, Llinas R (1998) Kinetic and stochastic properties of a persistent sodium current in mature guinea pig cerebellar Purkinje cells. J Neurophysiol 80:1167-1179.

Kiehn O, Kjaerulff O, Tresch MC, Harris-Warrick RM (2000) Contributions of intrinsic motor neuron properties to the production of rhythmic motor output in the mammalian spinal cord. Brain Res Bull 53:649-659.

Koch C (1984) Cable theory in neurons with active, linearized membranes. Biol Cybern 50:15-33.

Kononenko NI, Dudek FE (2006) Persistent calcium current in rat suprachiasmatic nucleus neurons. Neuroscience 138:377-388.

Kuo JJ, Lee RH, Johnson MD, Heckman HM, Heckman CJ (2003) Active dendritic integration of inhibitory synaptic inputs in vivo. J Neurophysiol 90:3617-3624.

Kuo JJ, Lee RH, Zhang L, Heckman CJ (2006) Essential role of the persistent sodium current in spike initiation during slowly rising inputs in mouse spinal neurones. J Physiol (Lond) 574:819-834.

Lee RH, Heckman CJ (1999) Paradoxical effect of QX-314 on persistent inward currents and bistable behavior in spinal motoneurons in vivo. J Neurophysiol 82:2518-2527.

Lee RH, Heckman CJ (2000) Adjustable amplification of synaptic input in the dendrites of spinal motoneurons in vivo. J Neurosci 20:6734-6740.

Lee RH, Heckman CJ (2001) Essential role of a fast persistent inward current in action potential initiation and control of rhythmic firing. J Neurophysiol 85:472-475.

Lee RH, Kuo JJ, Jiang MC, Heckman CJ (2003) Influence of active dendritic currents on input-output processing in spinal motoneurons in vivo. J Neurophysiol 89:27-39.

Li Y, Bennett DJ (2003) Persistent sodium and calcium currents cause plateau potentials in motoneurons of chronic spinal rats. J Neurophysiol 90:857-869.

Li Y, Gorassini MA, Bennett DJ (2004) Role of persistent sodium and calcium currents in motoneuron firing and spasticity in chronic spinal rats. J Neurophysiol 91:767-783.

Lipscombe D, Pan JQ, Gray AC (2002) Functional diversity in neuronal voltage-gated calcium channels by alternative splicing of $\mathrm{Ca}(\mathrm{v})$ alphal. Mol Neurobiol 26:21-44.

Manuel M, Meunier C, Donnet M, Zytnicki D (2005) How much afterhyperpolarization conductance is recruited by an action potential? A dynamic-clamp study in cat lumbar motoneurons. J Neurosci 25:8917-8923.

Matthews PB (1963) The response of de-efferented muscle spindle receptors to stretching at different velocities. J Physiol (Lond) 168:660-678.

Matthews PB (1964) Muscle spindles and their motor control. Physiol Rev 44:219-288.

McLarnon JG (1995) Potassium currents in motoneurones. Prog Neurobiol 47:513-531.

Mermelstein PG, Bito H, Deisseroth K, Tsien RW (2000) Critical dependence of cAMP response element-binding protein phosphorylation on L-type calcium channels supports a selective response to EPSPs in preference to action potentials. J Neurosci 20:266-273.
Milligan CJ, Edwards IJ, Deuchars J (2006) HCN1 ion channel immunoreactivity in spinal cord and medulla oblongata. Brain Res 1081:79-91.

Morisset V, Nagy F (2000) Plateau potential-dependent windup of the response to primary afferent stimuli in rat dorsal horn neurons. Eur J Neurosci 12:3087-3095.

Nguyen QT, Wessel R, Kleinfeld D (2004) Developmental regulation of active and passive membrane properties in rat vibrissa motoneurones. J Physiol (Lond) 556:203-219.

Pape HC (1996) Queer current and pacemaker: the hyperpolarizationactivated cation current in neurons. Annu Rev Physiol 58:299-327.

Perkins KL, Wong RK (1995) Intracellular QX-314 blocks the hyperpolarization-activated inward current Iq in hippocampal CA1 pyramidal cells. J Neurophysiol 73:911-915.

Powers RK, Binder MD (2001) Input-output functions of mammalian motoneurons. Rev Physiol Biochem Pharmacol 143:137-263.

Powers RK, Binder MD (2003) Persistent sodium and calcium currents in rat hypoglossal motoneurons. J Neurophysiol 89:615-624.

Prather JF, Powers RK, Cope TC (2001) Amplification and linear summation of synaptic effects on motoneuron firing rate. J Neurophysiol 85:43-53.

Prinz AA, Abbott LF, Marder E (2004) The dynamic clamp comes of age. Trends Neurosci 27:218-224.

Puil E, Gimbarzevsky B, Spigelman I (1988) Primary involvement of $\mathrm{K}^{+}$ conductance in membrane resonance of trigeminal root ganglion neurons. J Neurophysiol 59:77-89.

Raikov I, Preyer A, Butera RJ (2004) MRCI: a flexible real-time dynamic clamp system for electrophysiology experiments. J Neurosci Methods 132:109-123.

Rall W (1959) Branching dendritic trees and motoneuron membrane resistivity. Exp Neurol 1:491-527.

Richardson MJ, Brunel N, Hakim V (2003) From subthreshold to firingrate resonance. J Neurophysiol 89:2538-2554.

Santoro B, Chen S, Luthi A, Pavlidis P, Shumyatsky GP, Tibbs GR, Siegelbaum SA (2000) Molecular and functional heterogeneity of hyperpolarization-activated pacemaker channels in the mouse CNS. J Neurosci 20:5264-5275.

Sayer RJ, Brown AM, Schwindt PC, Crill WE (1993) Calcium currents in acutely isolated human neocortical neurons. J Neurophysiol 69:1596-1606.

Schwindt P, Crill W (1980) Role of a persistent inward current in motoneuron bursting during spinal seizures. J Neurophysiol 43:1296-1318.

Schwindt PC, Crill WE (1984) Membrane properties of cat spinal motoneurons. In: Handbook of the spinal cord (Davidoff RA, ed), pp 199-267. New York: Dekker.

Schwindt PC, Crill WE (1995) Amplification of synaptic current by persistent sodium conductance in apical dendrite of neocortical neurons. J Neurophysiol 74:2220-2224.

Takahashi T (1990) Inward rectification in neonatal rat spinal motoneurones. J Physiol (Lond) 423:47-62.

Wu N, Enomoto A, Tanaka S, Hsiao CF, Nykamp DQ, Izhikevich E, Chandler SH (2005) Persistent sodium currents in mesencephalic v neurons participate in burst generation and control of membrane excitability. J Neurophysiol 93:2710-2722. 